\title{
In vitro, in vivo and ex vivo demonstration of the antitumoral role of hypocretin-1/orexin-A and almorexant in pancreatic ductal adenocarcinoma
}

\author{
Stéphanie Dayot ${ }^{1, *}$, Daniela Speisky ${ }^{1, *}$, Anne Couvelard ${ }^{1,2}$, Pierre Bourgoin ${ }^{1}$, Valérie \\ Gratio $^{1}$, Jérôme Cros $^{1,4}$, Vinciane Rebours ${ }^{1,3}$, Alain Sauvanet ${ }^{1,3}$, Pierre Bedossa $^{1,4}$, \\ Valérie Paradis ${ }^{1,4}$, Philippe Ruszniewski ${ }^{1,3}$, Alain Couvineau ${ }^{1, \#}$ and Thierry Voisin ${ }^{1, \#}$ \\ ${ }^{1}$ INSERM UMR1149 Centre de Recherche sur I'Inflammation (CRI), Université Paris-Diderot, Sorbonne Paris Cité, DHU UNITY, \\ Faculté de Médecine Xavier Bichat, Huchard, 75018 Paris, France \\ ${ }^{2}$ Département de Pathologie Beaujon-Bichat, AP-HP, Hôpital Bichat, Huchard, 75018 Paris, France \\ ${ }^{3}$ Service de Pancréatologie-Gastroentérologie PMAD, Pôle des Maladies de I'Appareil Digestif, AP-HP, Hôpital Beaujon, 92118 \\ Clichy, France \\ ${ }^{4}$ Département de Pathologie Beaujon-Bichat, AP-HP, Hôpital Beaujon, 92118 Clichy, France \\ *These authors contributed equally to this work \\ \#Shared last authors \\ Correspondence to: Thierry Voisin, email: thierry.voisin@inserm.fr \\ Alain Couvineau, email: alain.couvineau@inserm.fr \\ Keywords: pancreatic cancer; orexin receptor; GPCR; apoptosis; patient-derived xenograft \\ Received: July 29, $2017 \quad$ Accepted: January 02, $2018 \quad$ Published: January 09, 2018 \\ Copyright: Dayot et al. This is an open-access article distributed under the terms of the Creative Commons Attribution License 3.0 \\ (CC BY 3.0), which permits unrestricted use, distribution, and reproduction in any medium, provided the original author and source \\ are credited.
}

\section{ABSTRACT}

Pancreatic ductal adenocarcinoma (PDAC) is still the poorest prognostic tumor of the digestive system. We investigated the antitumoral role of orexin-A and almorexant in PDAC. We analyzed the orexin receptor type 1 (OX1R) expression by immunohistochemistry in human normal pancreas, PDAC and its precursor dysplastic intraepithelial lesions. We used PDAC-derived cell lines and fresh tissue slices to study the apoptotic role of hypocretin-1/orexin-A and almorexant in vitro and ex vivo. We analyzed in vivo the hypocretin-1/orexin-A and almorexant effect on tumor growth in mice xenografted with PDAC cell lines expressing, or not, OX1R. Ninety-six percent of PDAC expressed OX1R, while adjacent normal exocrine pancreas did not. OX1R was expressed in pre-cancerous lesions. In vitro, under hypocretin-1/orexin-A and almorexant, the OX1R-positive AsPC-1 cells underwent apoptosis, abolished by the tyrosine phosphatase SHP2 inhibitor, NSC-87877, whereas the OX1R-negative HPAF-II cell line did not. These effects were mediated by phosphorylation of OX1R and recruitment of SHP2. EX vivo, caspase-3 positive tumor cells were significantly higher in fresh tumour slices treated $48 \mathrm{~h}$ with hypocretin-1/orexin-A, as compared to control, whereas cellular proliferation, assessed by Ki-67 index, was not modified. In vivo, when AsPC-1 cells or patient-derived cells were xenografted in nude mice, hypocretin-1/orexin-A or almorexant, administrated both starting the day of cell line inoculation or after tumoral development, strongly slowed tumor growth. Hypocretin-1/orexin-A and almorexant induce, through OX1R, the inhibition of PDAC cellular growth by apoptosis. Hypocretins/orexins and almorexant might be powerful candidates for the treatment of PDAC. 


\section{INTRODUCTION}

Pancreatic ductal adenocarcinoma (PDAC) is the eleventh most frequent cancer in the United States, accounting for 53,070 new cases per year, and it will stand as the second cause of cancer related-death by 2030 [1-4]. The low 5-year survival rate (about 7\%) is due to highly invasive behavior with frequent non-resectability at initial diagnosis. Moreover this tumor is mainly drugresistant to classic chemotherapeutic agents because of the association of a fibrotic, immunosuppressive, and hypoxic microenvironment with numerous tumor mutations that activate proto-oncogene expression, block tumor suppressor genes or interfere with apoptosis [5]. Thus far and despite intense efforts, optimal chemotherapeutic strategies have only slightly improved clinical outcome in patients with PDAC.

G-protein coupled receptors (GPCRs) belong to a large superfamily of cell surface signaling proteins involved in many pathophysiological processes [6]. Diverse GPCRs are overexpressed in tumor cells, and are involved in the initiation and/or progression of cancer by stimulating or inhibiting proliferation and/or apoptosis [7]. We have recently demonstrated the aberrant expression of the orexin receptor sub-type $1, \mathrm{OX} 1 \mathrm{R}$, in primary colorectal tumors, whereas no expression could be found in normal colon [8].

Orexin-A and orexin-B [9], are two hypothalamic neuropeptides involved in the sleep/wake cycle and feeding behavior [10]. In this context, pharmaceutical industries have developed several orexin antagonists (Dual Orexin Receptors Antagonist or DORA) including almorexant and suvorexant in order to promote the sleep control. Recently, the U.S. Food \& Drug Administration (FDA) approved the use of a reversible dual orexin receptor antagonist suvorexant, for the treatment of insomnia. Biological functions of orexins have been described in various peripheral tissues, but remain questionable [11-14]. The effects of orexins are mediated by two GPCR sub-types, OX1R and OX2R [9]. The activation of OX1R and OX2R by orexins led to the intracellular $\mathrm{Ca}^{2+}$ mobilization which was inhibited by orexin antagonists. In OX1R expressing cell lines, we have shown that OX1R triggers a robust mitochondrial apoptosis by an original mechanism [8, 15]. Activation of OX1R induces the tyrosine phosphorylation of 2 tyrosinebased motifs, ITIM (immunoreceptor tyrosine-based inhibition motif), of OX1R, which allow the recruitment of the phosphotyrosine phosphatase SHP-2 and the caspase-3 activation [16-18].

PDAC cells gain protection against the apoptotic mitochondrial pathway by overexpressing Bcl-family proteins (Bfl1, BCL-X $\left.{ }_{L}, \mathrm{MCL}-1\right)$ [19] or by blocking activation of caspases - e.g., by overexpressing caspase inhibitors (cIAP, XIAP1, survivin), epigenetic downregulation of pro-caspase gene expression or direct caspase inhibition by cysteine nitrosylation [20, 21]. Novel strategies aim at the commitment of PDAC cells to undergo apoptosis efficiently in response to novel drugs. In this context, studying the role and expression of the proapoptotic orexin receptor OX1R in PDAC represents a promising approach. We showed that the receptor $\mathrm{OX} 1 \mathrm{R}$ is not present in normal exocrine pancreas but is aberrantly expressed in almost all primary PDAC tested. We also investigated the ability of orexin-A to promote apoptosis: 1) in vitro studies by using PDAC cell lines as AsPC-1 cells; 2) ex vivo studies by using tissue culture derived from patients. We showed that orexin-A strongly reduced the development of tumors and reversed the growth of developed tumors in nude mice xenografted with human pancreas cancer cell line or patient-derived cells. Surprisingly, almorexant which is a $\mathrm{Ca}^{2+}$ pathway DORA antagonist, behaves as full apoptotic pathway agonist. These data indicate that OX1R, OxA and almorexant might be considered as novel candidates for PDAC therapy.

\section{RESULTS}

\section{Aberrant OX1R expression in PDAC}

\section{Human PDAC in TMA}

Seventy primary PDAC (70/73; 96\%) expressed OX1R by immunohistochemistry, as shown in Figure 1A and $1 \mathrm{~B}$. OX1R expression was mainly cytoplasmic and membranous. Scores ranged from 90 to 300 (median: 188). Only three tumors did not show any immunoreactivity for OX1R $(3 / 73 ; 4 \%)$. OX1R expression in PDAC was not correlated with patient age, gender, disease recurrence, disease-free survival, overall survival, tumor size, TNM stage, lymph node metastasis, or tumor differentiation (Table 1).

\section{Human PanIN and normal pancreas}

OX1R was expressed in 20/20 (100\%) PanIN lesions. Its expression was higher in PanIN-3 as compared to PanIN-1/2 ( $p<0.005$; Figure $1 \mathrm{C}$ and $1 \mathrm{D})$. In contrast, no OX1R immunodetection was observed in normal exocrine pancreas, including acinar and ductal cells; OX1R was restricted to islets in normal pancreas (Figure 1E and $1 \mathrm{~F}$ ).

\section{OX1R expression in AsPC-1 cell line}

As shown in Figure 2A, an amplified single specific $500 \mathrm{bp}$ PCR product corresponding to OX1R transcript was detected in the AsPC-1 cell line. $\mathrm{CHO}$ cells expressing recombinant $\mathrm{OX} 1 \mathrm{R}$ receptor were used as control. No OX1R transcript was detected in the SW 1990 and HPAFII cancer cell lines. As shown in Figure 2A, no mRNA could be detected for the other orexin receptor subtype, $\mathrm{OX} 2 \mathrm{R}$, in any cell lines tested as compared to control recombinant $\mathrm{CHO} / \mathrm{OX} 2 \mathrm{R}$ cells. 
These data are in full agreement with the immunostaining data for OX1R in AsPC-1 and HPAF-II cell lines included in cell-blocks: specific OX1R immunodetection was observed in AsPC-1 cell membranes whereas no OX1R expression could be seen in the HPAFII cell line (Figure 2B)

\section{Orexin-A effect in vitro cell line models}

Orexin-A induced a drastic inhibition of cellular growth of AsPC-1 cells, associated with the induction of mitochondrial apoptosis, characterized by recruitment of the tyrosine phosphatase SHP-2 and followed by the activation of caspase- 3 . One $\mu \mathrm{M}$ orexin-A induced a strong increase of annexin- $\mathrm{V}$ positive AsPC-1 cells
$(24.3 \% \pm 1.4)$ as compared to untreated cells $(3.8 \% \pm$ 1.9) (Figure 3A). In the presence of the specific SHP2 inhibitor, NSC 87877, the orexin-A-induced apoptosis was totally abolished (Figure 3A), in agreement with the involvement of a SHP-2-dependent apoptosis signaling pathway. No significant difference was observed in the NSC 87877-treated AsPC-1 cells in the presence (4.8\% $0.5)$ or absence of $1 \mu \mathrm{M}$ orexin-A $(4.6 \% \pm 0.9)$. Moreover, $1 \mu \mathrm{M}$ orexin-A induced the cleavage and activation of caspase-3, as seen by immunohistochemistry, whereas no activated caspase-3 was detected in untreated cells (Figure 3B). The quantification of the staining demonstrated that orexin-A induced a 4-fold increase in activated caspase- 3 as compared to basal conditions (Figure 3C).
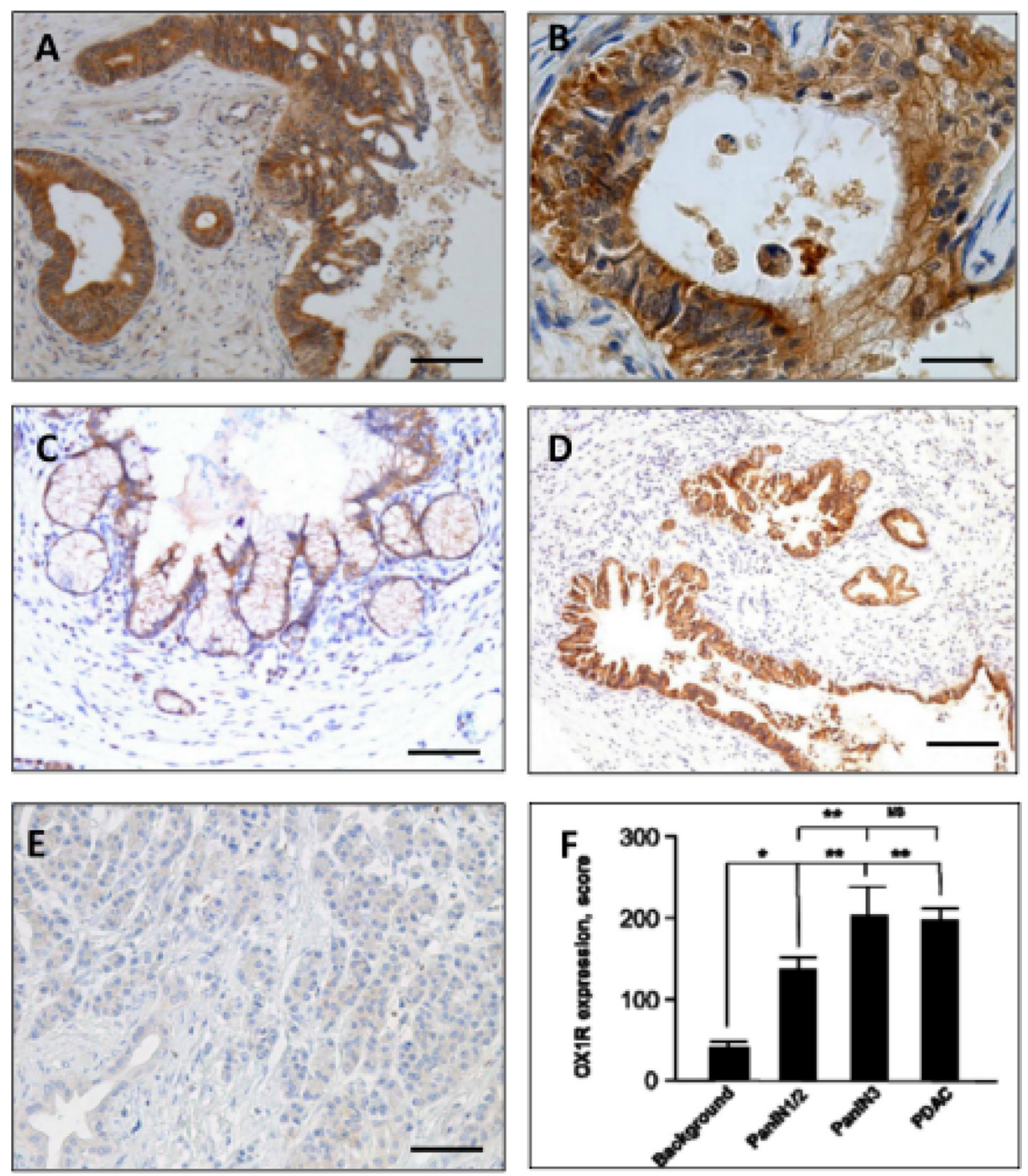

Figure 1: Immunohistochemical expression of the Orexin Receptor (OX1R) by PDAC (A and B), PanIN lesions (C and D) and normal pancreas (E) - OX1R is strongly expressed by tumor cells in PDAC, but is not detected in the surrounding stroma (A); at higher magnification, the staining is located to the membrane (arrows, B) and cytoplasm, and scored at 300 (intensity 3 on $100 \%$ of tumor cells, see "Materials and Methods"). OX1R was not detected in the normal pancreas (E) either in normal duct and acinar cells. OX1R was faintly expressed in a PanIN-1/2 lesion (C) and strongly expressed in a PanIN-3 lesion (D). Bar $=200 \mu \mathrm{m}$ for (A), $50 \mu \mathrm{m}$ for (B), $120 \mu \mathrm{m}$ for (C), $400 \mu \mathrm{m}$ for (D) and $120 \mu \mathrm{m}$ for $(\mathrm{E})$. OX1R immunostaining is scored in panel (F). ${ }^{*} p<0.05 ;{ }^{* *} p<0.005$ and ns, non-significant. 
Table 1: Correlation of OX1R expression and main histopathological and clinical factors

\begin{tabular}{|c|c|c|c|}
\hline & OX1R > median & OX1R < median & $p$ value \\
\hline $\mathrm{T} 1$ or $\mathrm{T} 2$ & 4 & 7 & \multirow{2}{*}{ NS } \\
\hline $\mathrm{T} 3$ & 32 & 27 & \\
\hline $\mathrm{NO}$ & 8 & 10 & \multirow{2}{*}{ NS } \\
\hline N1 & 28 & 24 & \\
\hline Tumor size $<30 \mathrm{~mm}$ & 16 & 15 & \multirow{2}{*}{ NS } \\
\hline Tumor size $\geq 30 \mathrm{~mm}$ & 20 & 19 & \\
\hline Well-differentiated & 19 & 17 & \multirow{2}{*}{ NS } \\
\hline $\mathrm{M}$ or $\mathrm{P}$ differentiated & 18 & 17 & \\
\hline Recurrence & 29 & 24 & \multirow{2}{*}{ NS } \\
\hline No recurrence & 7 & 10 & \\
\hline Dead of disease & 28 & 27 & \multirow{2}{*}{ NS } \\
\hline Alive & 8 & 7 & \\
\hline
\end{tabular}

NO: no lymph node metastasis; N1: presence of lymph node metastasis; $\mathrm{M}$ or P: moderately or poorly.
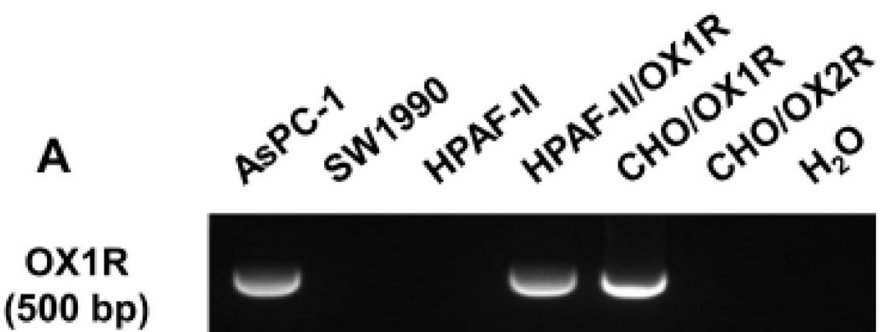

OX2R

(500 bp)

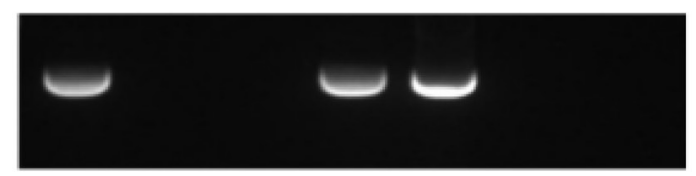

$\beta$-actin

$(838 \mathrm{bp})$

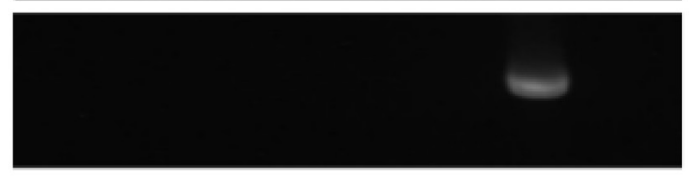

B
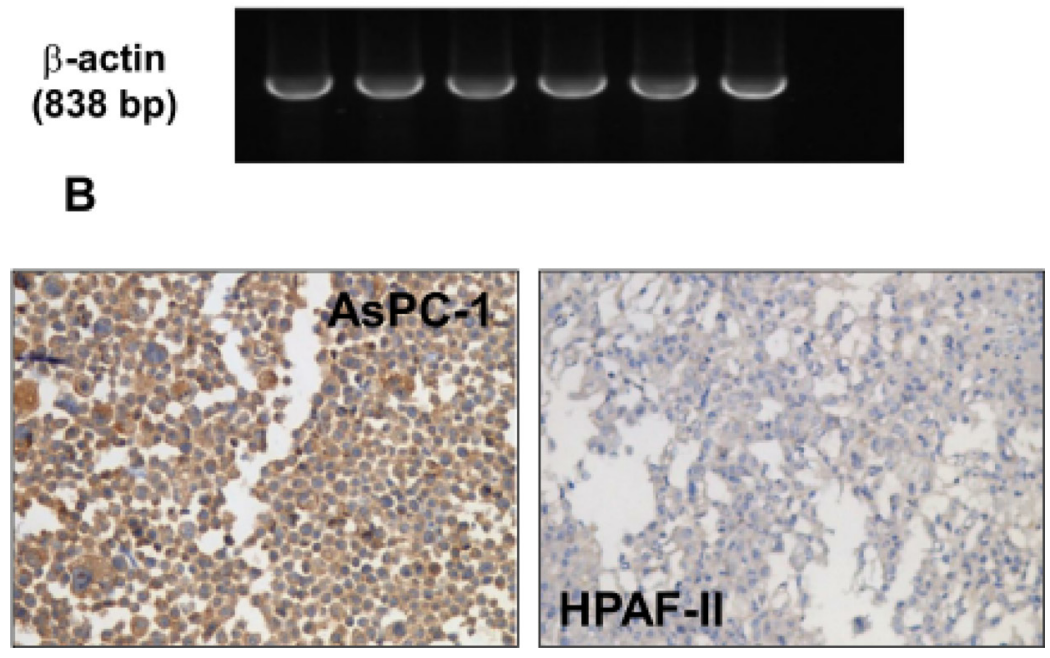

Figure 2: Expression of OX1R in PDCA cells - (A) shows RT-PCR analysis of OX1R (top panel) or OX2R (middle panel) mRNA from AsPC-1 cells, SW1990 cells, parental HPAF-II cell, HPAF-II cells expressing recombinant OX1R, CHO/OX1R cells, and CHO/OX2R cells. Controls are shown in the last lane $\left(\mathrm{H}_{2} \mathrm{O}\right)$ in absence of DNA template. RT-PCR analysis of $\beta$-actin mRNA was used as control (bottom panel). (B) shows the immunostaining of OX1R in paraformaldehyde-fixed and paraffin-embedded section from pellets of AsPC-1 cells (left panel) and HPAF-II cells (right panel) cultured in standard medium in the presence of FCS. 
In order to demonstrate the specific proapoptotic role of OX1R in PDAC, we expressed recombinant OX1R in HPAF-II cells, which do not express this receptor. In parental HPAF-II cells, treatment with $1 \mu \mathrm{M}$ orexin-A did not induce apoptosis (Figure 4A). Inversely, treatment of recombinant HPAF-II expressing OX1R cells with $1 \mu \mathrm{M}$ orexin-A resulted in the strong induction of cellular apoptosis as indicated by $17.8 \% \pm 2.4$ annexin- $\mathrm{V}$ positive apoptotic cells (Figure 4A) compared to $2.1 \% \pm 0.4$ in untransfected cells. In addition, NSC87877 totally abolished orexin-A-induced apoptosis in OX1R-expressing HPAF-II cells (Figure 4A), whereas this inhibitor had no effect on the parental cells. Similarly, orexin-A induced a strong caspase- 3 activation in recombinant OX1R/HPAFII cells while no activation was observed in the parental cells (Figure 4B). As previously demonstrated in colon cancer, orexin-A induced both OX1R phosphorylation and SHP2 recruitment by OX1R leading to apoptosis process [16]. After immunoprecipitation of SHP2/OX1R complex expressed in AsPC-1 cells, we observe that orexin-A promotes tyrosine phosphorylation of OX1R. However, in the presence of NSC87877 inhibitor, orexin-A was unable to stimulate tyrosine phosphorylation of receptor.
Inversely, in HPAF II cells which did not express OX1R, no tyrosine phosphorylation was observed in the presence of $1 \mu \mathrm{M}$ orexin-A (Figure 5).

These data strongly suggest that the mechanism involved in orexin-A-induced apoptosis in pancreatic cancer cells was similar in colon cancer cell lines as previously described $[8,16]$.

\section{Orexin-A effect in preclinical models}

\section{AsPC-1 xenografts}

Daily intraperitoneal injection of orexin-A ( $1 \mu \mathrm{mol} /$ $\mathrm{kg}$ ) at day 0 in mice xenografted with AsPC-1 cells and up to the mice sacrifices resulted in a significant decrease in tumor volume (48.8\%), as compared to untreated mice (Figure 6A). In addition, treatment with orexin-A started after AsPC-1 tumors were developed, 14 days after cell inoculation. Orexin-A ( $1 \mu \mathrm{mol} / \mathrm{kg})$, rapidly and strongly reduced the volume of established tumors (Figure 6A). After animal sacrifice, tumors were resected and weighted. No differences were observed in the weight of tumors from orexin-A treated mice at day 0 and orexin-A treated mice at

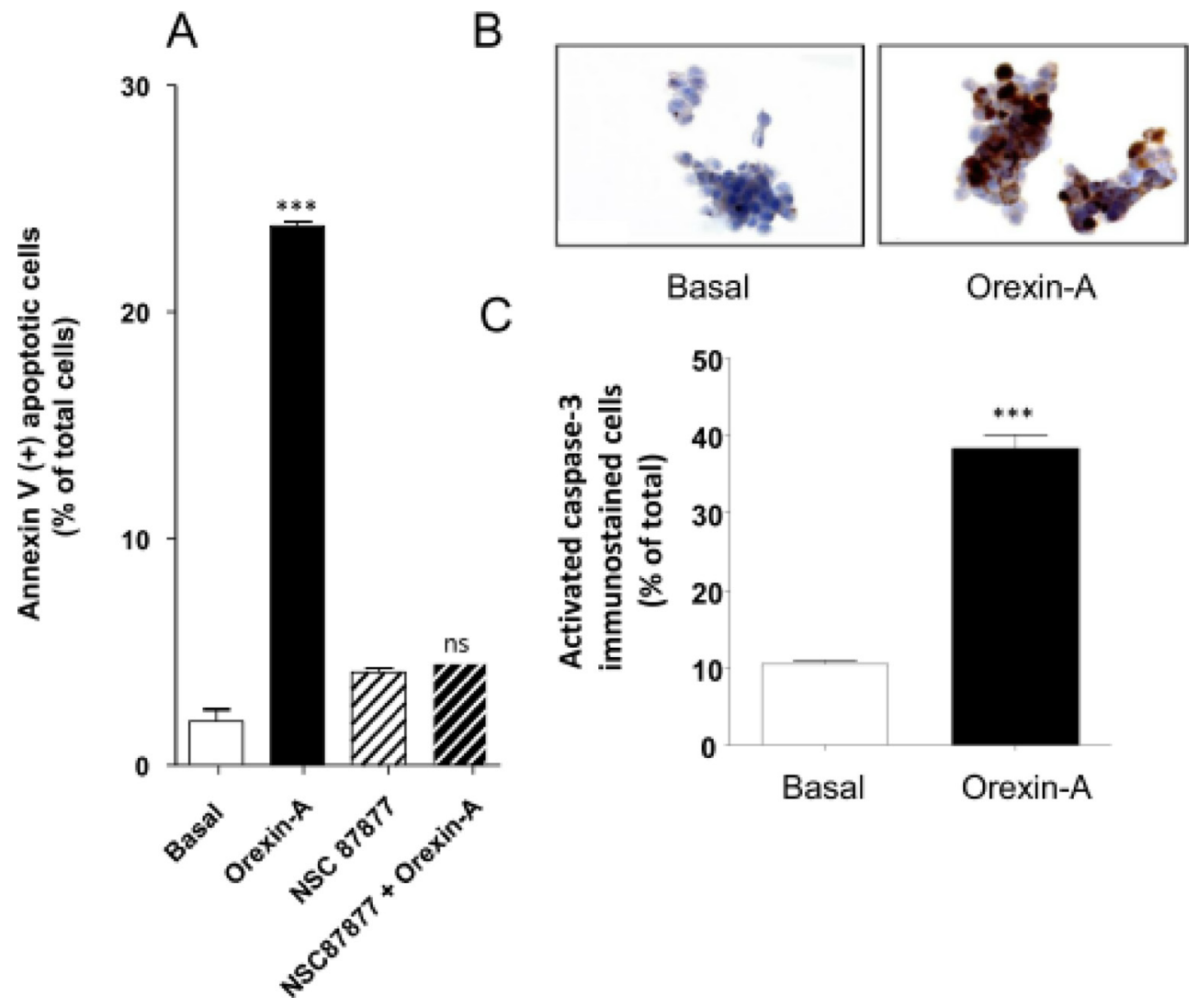

Figure 3: Effect of orexin-A on apoptosis in AsPC-1 cells - (A), SHP-2 protein tyrosine phosphatase inhibitor, NSC-87877, blocks orexininduced apoptosis. AsPC-1 cells were challenged with (black bars) or without (white bars) $1 \mu \mathrm{M}$ orexin-A for $48 \mathrm{hr}$ in the absence or presence of NSC-87877 $(50 \mu \mathrm{M})$. Apoptosis was measured by determination of annexin V-PE binding, and results are expressed as the percentage of apoptotic cells; (B) and (C). Indirect immunostaining of activated caspase-3 in AsPC-1 cells in the presence or absence of orexin-A. Paraformaldehyde-fixed AsPC-1 cells were challenged with (orexin-A) or without (basal) $1 \mu \mathrm{M}$ orexin-A for 48 hr. Activated caspase-3 immunostaining is shown in $\mathrm{B}$ and scored in $\mathrm{C}$. Results are means $\pm \mathrm{SE}$ of three separate experiments. ${ }^{* * *} p<0.001$; ns, non-significant. 
day 14 after cell inoculation (Figure 6A, insert). The effect of orexin-A on tumor volume was dose-dependent as a 30 day treatment with $0.01,0.1,1$ and $10 \mu$ moles orexin- $\mathrm{A} / \mathrm{kg}$ decreased the tumor volumes by $34.4,30.6,46.7$, and $52.8 \%$, respectively (Figure $6 \mathrm{~B}$ ). These data correlated with tumor weight (Figure 6B). Hematoxylin and eosin staining of resected tumors revealed the same glandular differentiation in both treated and non-treated tumors (Figure 6C, panels a and d). OX1R immunostaining level was not affected by orexin-A treatment, suggesting that OX1R expression is not
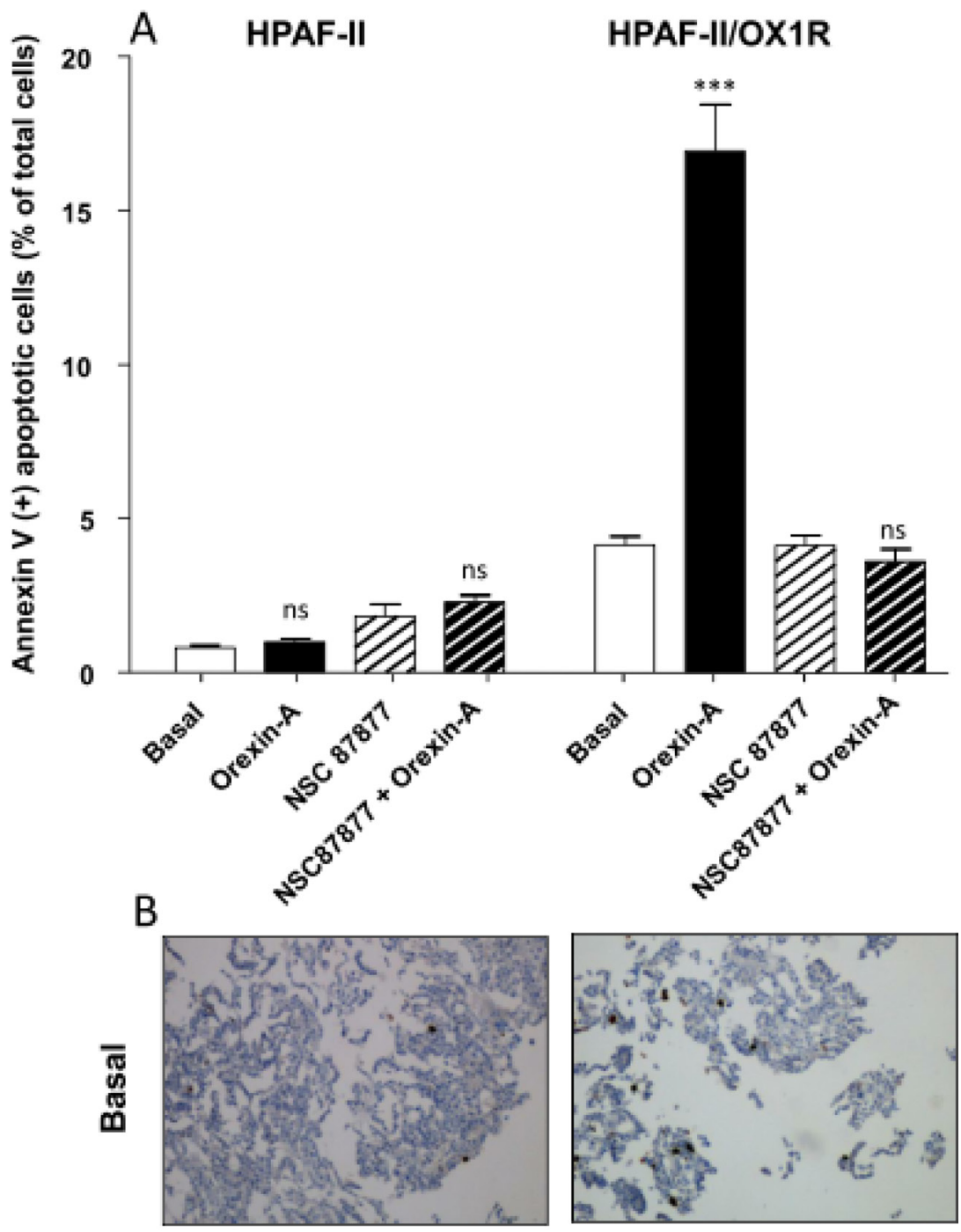

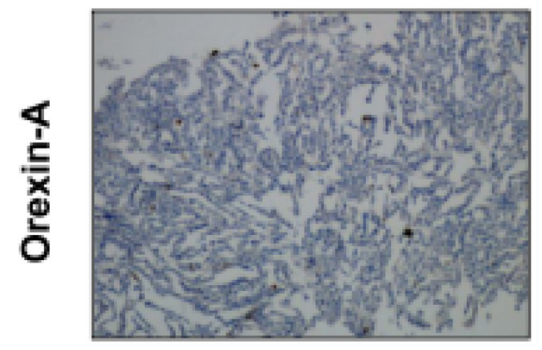

HPAF-II

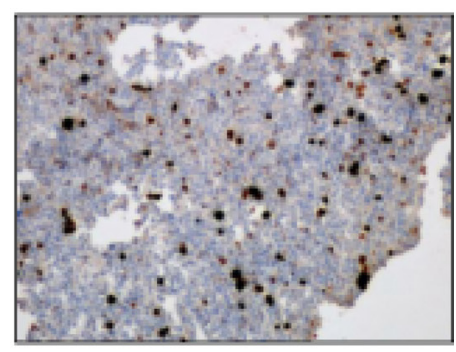

HPAF-II/OX1R

Figure 4: Effect of orexin-A on apoptosis in OX1R expressing recombinant OX1R/HPAF-II cells - (A), Parental HPAF-II and recombinant OX1R/HPAF-II cells were challenged with (black bars) or without (white bars) $1 \mu \mathrm{M}$ orexin-A for $48 \mathrm{hr}$ in the absence or presence of the SHP-2 protein tyrosine phosphatase inhibitor, NSC-87877 $(50 \mu \mathrm{M})$. Apoptosis was measured by determination of annexin V-PE binding. Results are expressed as the percentage of apoptotic cells, and are the means $\pm \mathrm{SE}$ of three separate experiments. ${ }^{* * *} p<0.001$; ns, nonsignificant; (B), Paraformaldehyde-fixed HPAF-II cells and recombinant OX1R/HPAF-II cells were challenged with or without (Basal) $1 \mu \mathrm{M}$ orexin-A for $48 \mathrm{hr}$. Indirect immunostaining of activated caspase-3 in parental HPAF-II cells (left panels) and recombinant OX1R/ HPAF-II cells (right panels) in the presence (bottom panels) or tabsence (top panels) of orexin-A is illustrated in B. 
altered by chronic orexin-A treatment (Figure 6C, panels b and e). Furthermore, weak and intense staining of activated caspase-3 was observed in control (Figure 6C, panel c) and orexin-A treated (Figure 6C, panel f) mice, respectively.

\section{Patient-derived xenografts}

In an effort to develop more reliable preclinical models, we have established a subcutaneous patientderived xenograft (PDX) model. We have isolated cancerous cells from a human PDAC freshly resected. PDX cells were verified by the expression of OX1R (data not shown) and xenografted in mice. Daily intraperitoneal injection of orexin-A $(1 \mu \mathrm{mol} / \mathrm{kg})$ at day 0 in mice xenografted with PDX cells and up to the mice sacrifices resulted in a significant decrease in tumor volume (80\%), as compared to untreated mice (Figure 7). In addition, treatment with orexin-A started after PDX tumors were developed, 40 days after cell inoculation. Orexin-A ( $1 \mu \mathrm{mol} / \mathrm{kg}$ ), rapidly and strongly reduced the volume of established tumors (Figure 7).

\section{HPAF-II xenografts}

As mentioned above, we demonstrated the specific inhibitory effect of OX1R on tumor growth in HPAFII/OX1R xenografted in nude mice (Supplementary Figure 1). Daily treatment with $1 \mu \mathrm{mol}$ orexin-A/kg of mice xenografted with parental HPAF-II cells was unable to promote tumor growth inhibition. When mice were xenografted with recombinant HPAF-II/OX1R this treatment induced $65 \%$ inhibition of tumor development. Xenografted nude mice treated with orexin-A after 14 days of tumor growth showed significant reduction in tumor volumes. Orexin-A treatment promoted a 3.5-fold caspase- 3 expression by immunohistochemistry in tumors from recombinant HPAF-II/OX1R xenografted nude mice as compared to tumors from parental HPAF-II cells.

\section{Orexin-A effect in tumor explant models}

Significant OX1R immunostaining was observed in PDAC slices as compared to normal exocrine pancreas (score 227 vs 40; $p<0.0001$ ) (Figure 8A). We observed, in slices treated by orexin-A, an increase of activated caspase- 3 immunostaining in tumor cells as compared to the control slices without orexin-A treatment (Figure $8 \mathrm{~B}$ and $8 \mathrm{~F}$ and Table 2). Moreover, orexin-A treatment did not impact the cell proliferation (Figure 8C), neither ERK/MAPK and mTor signaling pathway (Figure 8D) nor surviving expression (Figure 8E). Taken all together, these results demonstrate that the OX1R/orexin-A pathway plays a crucial role in tumor growth inhibition.

\section{The $\mathrm{Ca}^{2+}$ pathway orexin receptors antagonist, almorexant acts also as an anti-tumoral agent}

The pharmacology of orexin/orexin receptors had widely developed in orexin-regulation of sleep background [22]. Recently, several orexin antagonists including almorexant and suvorexant had been described in order to control insomnia. In the present work, we have investigated the impact of almorexant and suvorexant, on their abilities to promote pro-apoptotic and anti-tumoral effects. As expected, suvorexant and almorexant totally blocked the intracellular $\mathrm{Ca}^{2+}$ signal pathway. Indeed, incubation

\section{IP anti-SHP2}

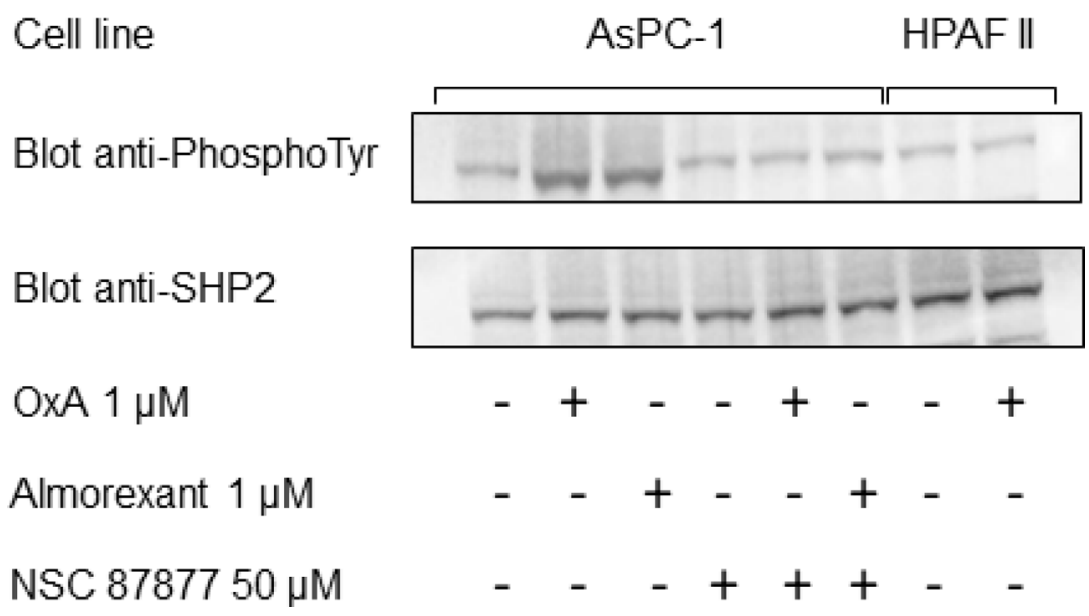

Figure 5: Orexin-A and almorexant promote tyrosine phosphorylation of SHP2/OX1R complex. AsPC-1 cells preincubated or not with the SHP2 inhibitor NSC-87877 $(50 \mu \mathrm{M})$ were challenged for 5 min without or with $1 \mu \mathrm{M}$ orexin-A or $1 \mu \mathrm{M}$ almorexant. In parallel, HPAF-II cells were also challenged for $5 \mathrm{~min}$ without or with $1 \mu \mathrm{M}$ orexin-A. After cell lysis, anti-SHP2 antibodies were used to obtain anti-SHP2 immunoprecipitates (IP) from $500 \mu \mathrm{g}$ of lysate protein. Western blot analysis was then performed using the antibodies anti-PhosphoTyrosine and anti-SHP2. 
of $1 \mu \mathrm{M}$ OxA with HEK-OX1R cells which expressed recombinant OX1R led to a massive increase of cytosolic $\mathrm{Ca}^{2+}$ mobilization (Figure 9A). In contrast, when HEKOX1R cells were incubated with $1 \mu \mathrm{M}$ OxA and $10 \mu \mathrm{M}$ suvorexant or almorexant, the $\mathrm{Ca}^{2+}$ mobilization was totally inhibited (Figure 9A). Surprisingly, $1 \mu \mathrm{M}$ of suvorexant or almorexant inhibited the cellular growth of AsPC-1 cells
(Figure 9B). However, almorexant is more potent than suvorexant in the AsPC-1 cell growth inhibition. Moreover, $1 \mu \mathrm{M}$ almorexant presents the similar effect than $1 \mu \mathrm{M}$ orexin-A inducing $37 \pm 4 \%$ and $36 \pm 4 \%$ cell death, respectively (Figure 9B). based on these observations, only almorexant will be used in next experiments. Almorexant-induced cell growth inhibition was totally

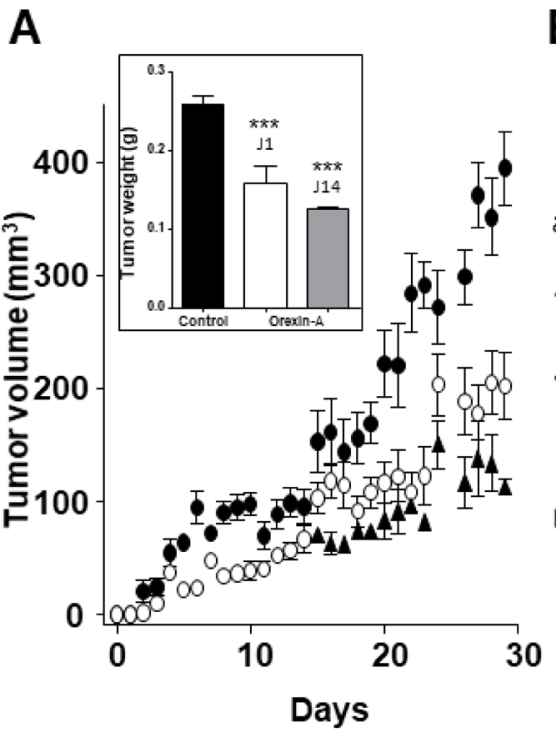

B
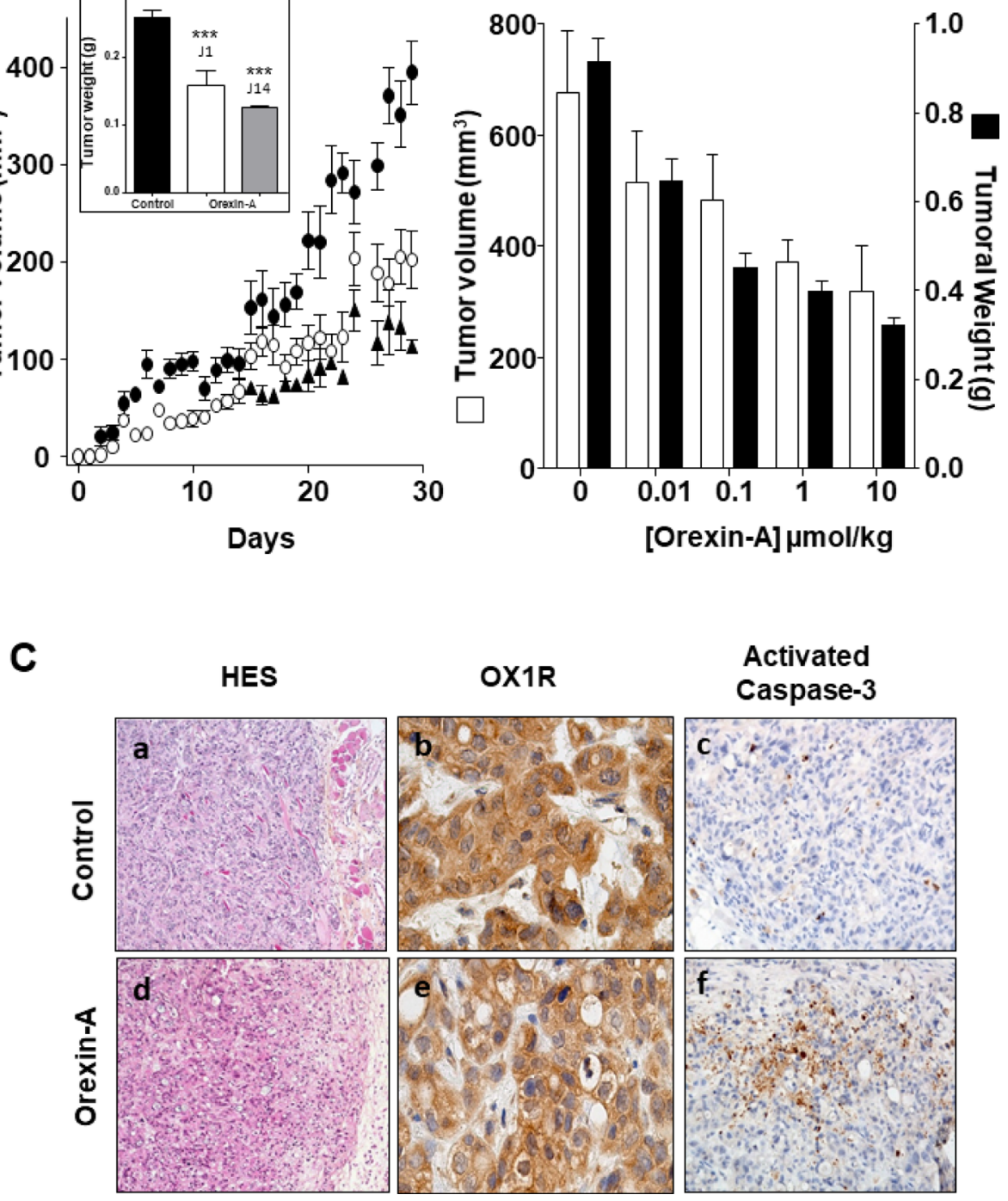

\section{OX1R}

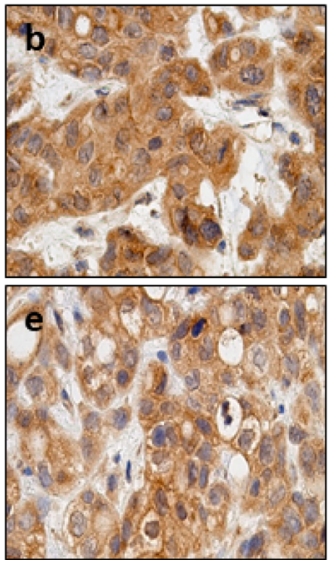

Activated Caspase-3

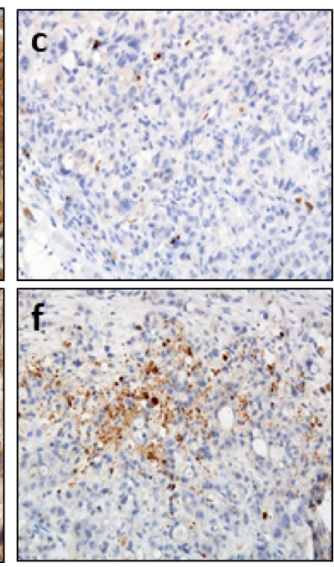

Figure 6: Effect of daily inoculation of orexin-A on the growth of tumors developed by xenografting human PDCA cells in nude mice - AsPC-1 cells were inoculated in the flank of nude mice at day 0 . Mice were injected daily intraperitoneally with $100 \mu$ l of orexin-A solutions starting at day $0(\mathrm{O})$ or day $14(\boldsymbol{\Delta})$ or with $100 \mu \mathrm{l}$ of PBS $(\bullet)$ for controls. (A) The daily treatment corresponded to $1 \mu$ moles of orexin- $\mathrm{A} / \mathrm{Kg}$. Inset represents the tumor weight measured at the end of the experiment after the mice were sacrificed; (B) Mice received $0.01,0.1,1$ or $10 \mu$ moles of orexin-A/Kg. After 30 days of treatment, mice were sacrificed and tumor volume and weight were then recorded. The developement of tumors was followed by caliper measurement. Data are the means $\pm \mathrm{SE}$ of 6 tumors in each group. ${ }^{* * *} p<0.001$ versus control. Indirect immunostaining of activated caspase- 3 in xenografted AsPC-1 tumors resected from nude mice (C) Paraformaldehyde-fixed xenografted AsPC-1 tumors from nude mice treated daily (panels d, e and f) by intraperitoneal injections with $1 \mu \mathrm{moles} / \mathrm{Kg}$ orexin-A or not (panels a, b and c). After necropsy, tumors were resected. Formalin-fixed paraffin-embedded tumours were cut in $3 \mu \mathrm{m}$ sections, which were either stained with hematoxylin-eosin or used for immunohistochemistry. Orexin-A induced tumoral cell death (panel d), as detected by Hemalum Eosin Safran (HES) staining, which correlated with apoptosis induction assessed by strong immunostaining of activated caspase- 3 after 30 days of orexin-A treatment; (panel f). OX1R immunostaining localisation was similar under control and orexin-A treatment conditions. 
abolished by NSC-87877 cell pre-treatment (Figure 9B). This effect was associated to almorexant-induced apoptosis, as shown in Figure 8C almorexant stimulates caspase-3 activity in AsPC-1 cells similarly to orexin-Ainduced caspase-3 activation (Figure 9C). As expected, cells pretreatment with NSC87877 inhibitor totally reversed this effect induced by almorexant and orexin-A (Figure 9C). Moreover, almorexant induced tyrosine phosphorylation of OX1R after immunoprecipitation of SHP2/OX1R complex in AsPC-1 cells. Almorexantinduced tyrosine phosphorylation of OX1R was totally inhibited in the presence of NSC87877 inhibitor (Figure 5). These data demonstrated that almorexant was able to induced apoptosis in pancreas cancer cells.

In this context, in vivo studies in preclinical model were investigated. Daily intraperitoneal injection of almorexant $(1.8 \mu \mathrm{mol} / \mathrm{kg})$ at day 0 in mice xenografted with AsPC-1 cells and up to the mice sacrifices resulted in a significant decrease in tumor volume $(>50 \%)$, as compared to untreated mice (Figure 10A). It should be noted that almorexant and orexin-A anti-tumoral effect were similar (Figure 6A and 10A). In addition, treatment with almorexant started after AsPC-1 tumors were developed, rapidly and strongly reduced the volume of established tumors (Figure 10A). OX1R expression revealed by immunodetection was not affected by almorexant treatment (Figure 10B).

\section{DISCUSSION}

We reported that $\mathrm{OX} 1 \mathrm{R}$ is aberrantly expressed in $96 \%$ of PDAC and $100 \%$ of PanIN, but not in normal acini and ducts adjacent to PDAC tissue although OX1R was expressed in islets. Orexin-A was able to promote apoptosis: 1) in vitro, in the PDAC cell line, AsPC-1;2) ex vivo, in tissue culture derived from patients. Furthermore, orexins strongly reduce the development of tumors in nude mice xenografted with human PDAC cells derived from cell line or PDX.

It is well known that PDAC are highly malignant neoplasms characterized by their poor prognosis and weak response to treatments [23]. In this regard, the expression of OX1R in primary PDAC tumors represents an essential element for new therapies as demonstrated previously in colon cancer by our group. [24, 25]. Because apoptosis is a highly controlled process regulated by different cellular signaling events, proapoptotic drugs are currently considered as attractive candidates in anticancer targeted therapies $[26,27]$. In the present work, we have demonstrated that the proapoptotic activity of OX1R

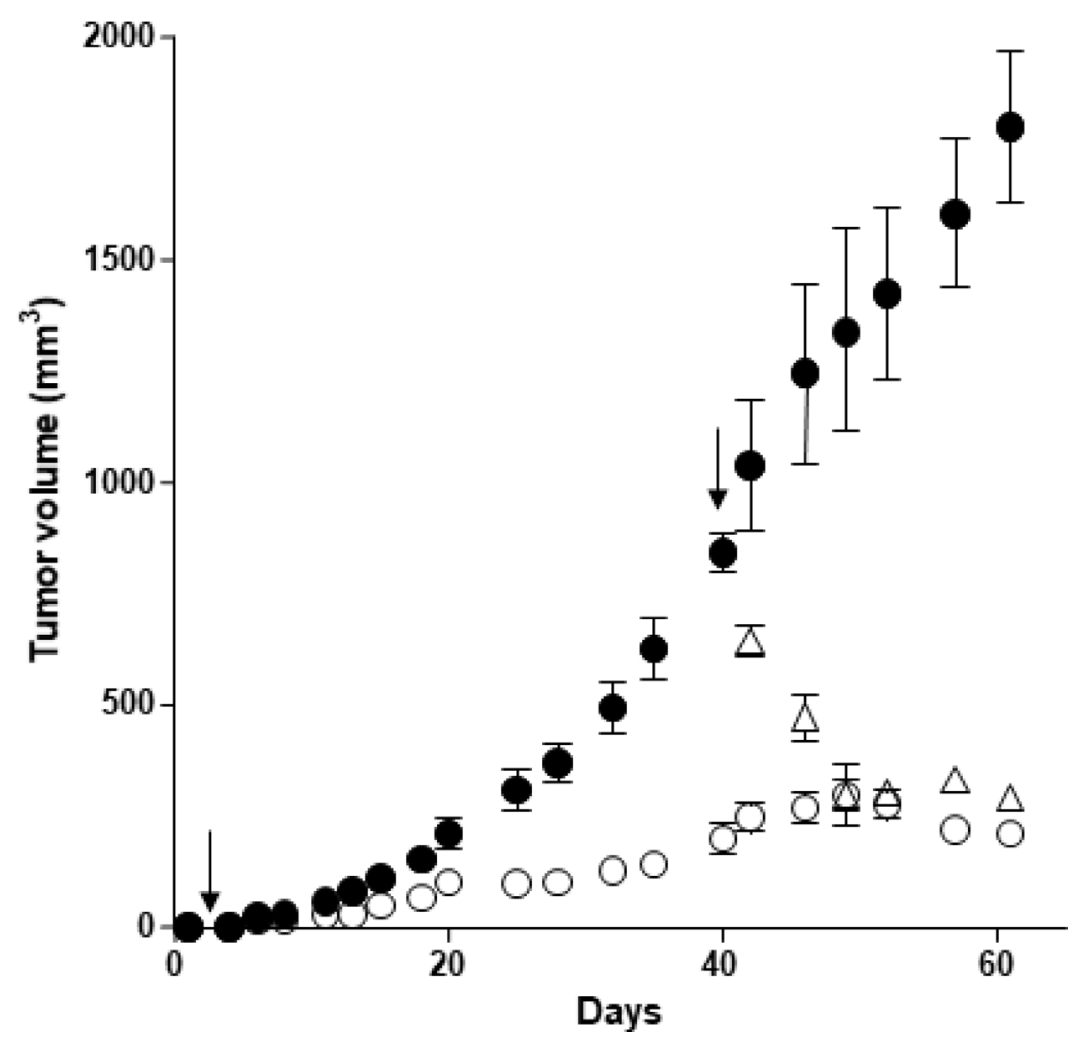

Figure 7: Effect of orexin-A inoculation on the growth of tumors developed by xenografting OX1R expressing pancreas cancer PDX cells in nude mice - PDX cells were inoculated $\left(10^{6}\right.$ cells per xenograft) in the flank of nude mice at day 0. Mice were injected ( 2 times/week) intraperitoneally with $100 \mu \mathrm{l}$ of $1 \mu$ moles of orexin-A/Kg solutions starting at day $1(\mathrm{O})$ or day $40(\Delta)$ or with $100 \mu \mathrm{l}$ of PBS $(\bullet)$ for controls. The development of tumors was followed by caliper measurement. Data are the means \pm SE of 6 tumors in each group; ${ }^{* * *} p<0.01$ versus control. 
correlates well with inhibition of cell growth in AsPC-1 pancreatic cell lines treated with orexin-A. The expression of recombinant $\mathrm{OX} 1 \mathrm{R}$ in a given cell line (HPAF-II) is sufficient to promote orexin-mediated apoptosis, highlighting the intrinsic property of the orexin receptor $[15,17]$. The proapoptotic properties of OX1R are mediated through recruitment of the tyrosine phosphatase SHP-2 [14, 16, 17] In our work, in the presence of NSC87877 , a potent inhibitor of SHP-2, the proapoptotic action of orexin-A was significantly reversed, confirming that SHP-2 activity is an essential step in OX1R-mediated apoptosis in PDAC.

Ex vivo experiments demonstrated that orexin-A was able to activate caspase- 3 in cultured tumor tissue removed from several patients showing the potential impact in the clinical setting. In contrast, orexin-A has no effect on the expression of proliferation marker, Ki67, confirming that orexin has no anti-proliferative properties [15].

In vivo experiments showed that orexin-A slows AsPC-1 tumor growth in a dose-dependent manner between 0.01 and $10 \mu$ Moles $/ \mathrm{kg}$. In addition, orexin-A was
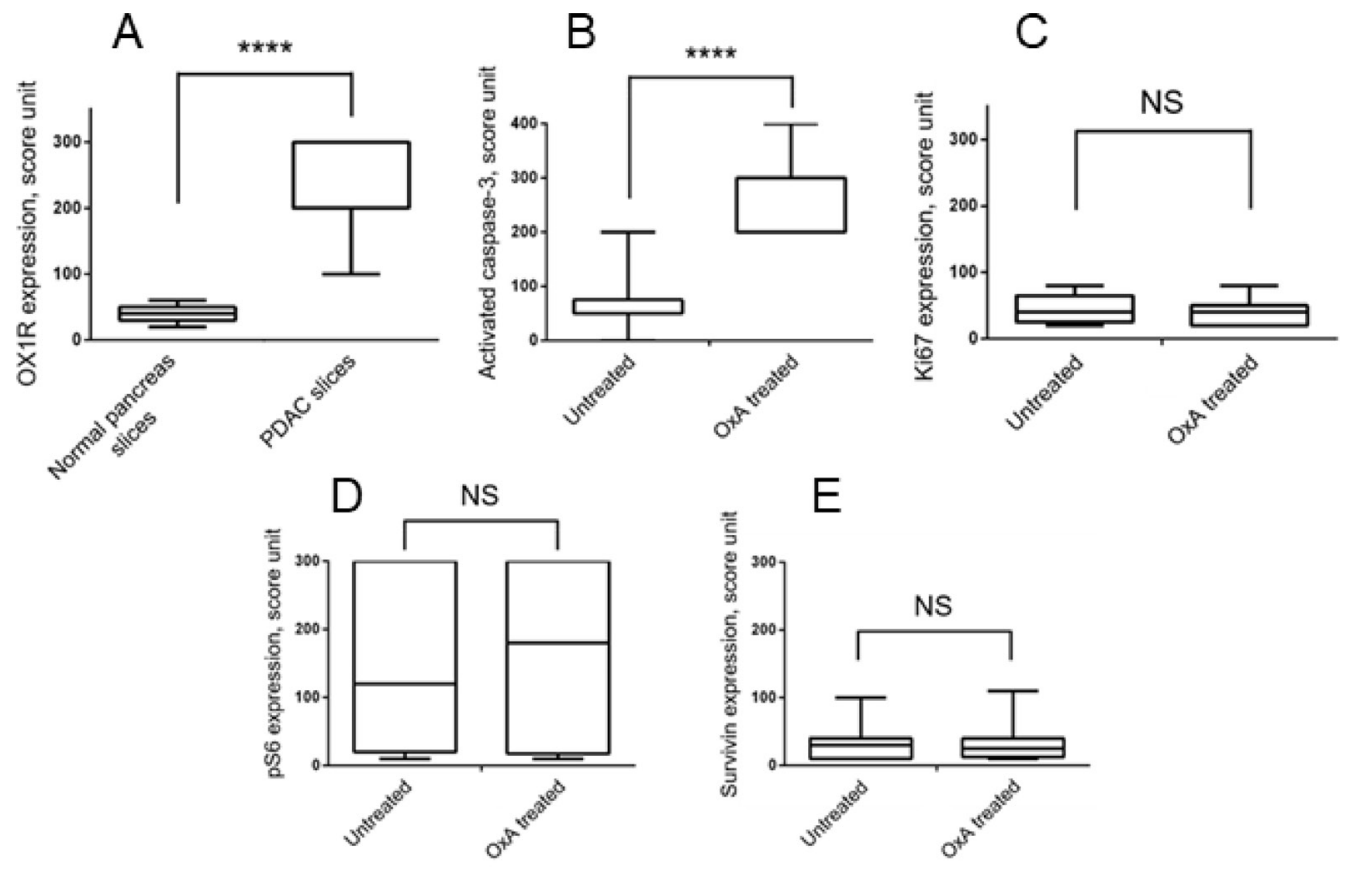

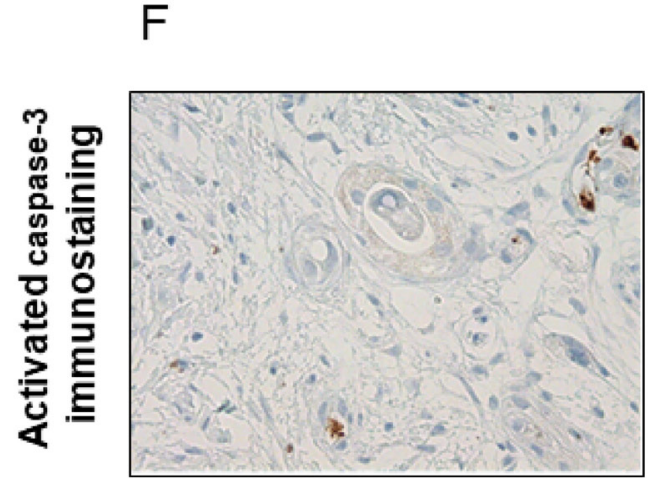

Control

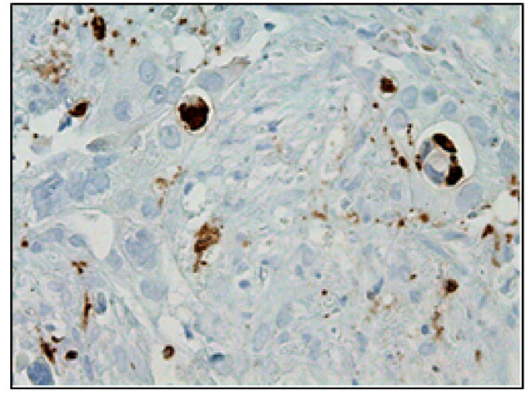

Orexin-A

Figure 8: Effect of orexin-A on whole tumor tissue samples from patients with PDAC. Panel A shows the score of OX1R expression in PDAC slices as compared to normal pancreas slices analysed by IHC. ${ }^{* * *} p<0.0001$ versus normal pancreas. The slice were treated for 24 hours with or without $1 \mu \mathrm{M}$ orexin-A in triplicates and fixed overnight in formalin and then embedded in paraffin. Serial $3 \mu \mathrm{m}$ thick sections were cut from the slices, stained by H\&E or used for immunohistochemical staining to assess activated caspase-3 (B), Ki67 (C), pS6 (D) or surviving (E). Tissue quality was assessed by a pathologist (AC). If tissue integrity was not maintained over time ( $>20 \%$ necrosis induction), tissues were discarded. Graphs display protein expression scoring of the IHC analysis of samples from 11 PDAC patients treated ex vivo with orexin-A were represented in panels B, C, D and E. ${ }^{* * *} p<0.001$ versus untreated, NS, no significant. Panel $\mathbf{F}$ represents a pancreatic ductal carcinoma after $24 \mathrm{~h}$ of slice culture with (orexin-A, panel right) or without $1 \mu \mathrm{M}$ orexin-A (control, left). 
Table 2: OX1R expression and effect of orexin-A on whole tumor tissue samples from patients with PDAC

\begin{tabular}{lccc}
\hline & Normal pancreas slices & PDAC slices & $\boldsymbol{p}$ value \\
\hline OX1R expression & $40 \pm 5$ & $227 \pm 23$ & 0.0001 \\
\hline & Untreated & OxA treated & $\boldsymbol{p}$ value \\
\hline Activated caspase & $67 \pm 19$ & $267 \pm 24$ & 0.0001 \\
Ki67 expression & $44 \pm 8$ & $40 \pm 8$ & 0.6912 \\
pS6 expression & $154 \pm 53$ & $165 \pm 61$ & 0.9115 \\
Survivin expression & $33 \pm 9$ & $35 \pm 12$ & 0.8964 \\
\hline
\end{tabular}

OX1R expression, activated caspase-3, Ki67, pS6 and survivin immunostaining are scored. Results are the means \pm SE of 11 independant patients.
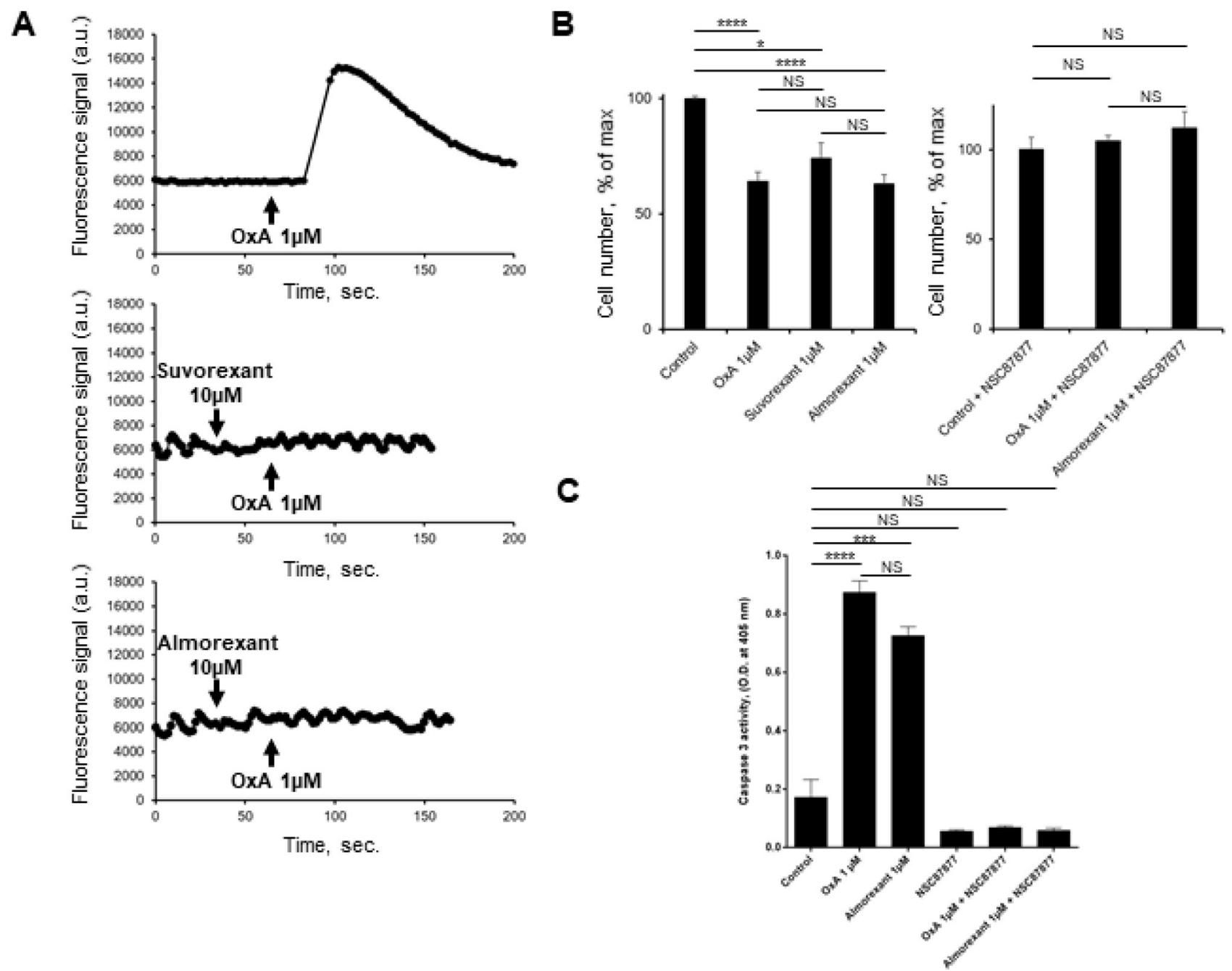

Figure 9: Effect of almorexant and suvorexant on intracellular $\mathrm{Ca}^{2+}$ release, cell growth and caspase-3 activity. (A) Intracellular $\mathrm{Ca}^{2+}$ production was detected in HEK-293 cells expressing recombinant native OX1R using Fluoforte Calcium Assay Kit (Enzo Life Sciences, NY, USA). Cells were challenged with $1 \mu \mathrm{M}$ of OxA (top panel) or $1 \mu \mathrm{M}$ OxA after preincubation with $10 \mu \mathrm{M}$ suvorexant (middle panel) or $10 \mu \mathrm{M}$ almorexant (bottom panel). (B) AsPC-1 cells were incubated for $48 \mathrm{~h}$ with OxA or almorexant or suvorexant in the presence (right panel) or in the absence (left panel) of $50 \mu \mathrm{M} \mathrm{NSC87877.} \mathrm{(C)} \mathrm{colorometric} \mathrm{Caspase-3} \mathrm{activity} \mathrm{detection}$ at $405 \mathrm{~nm}$ in AsPC-1 cells incubated with $1 \mu \mathrm{M}$ OxA or $1 \mu \mathrm{M}$ almorexant in the presence or in the absence of $50 \mu \mathrm{M}$ NSC87877. ${ }^{*} p<0.05$, ${ }^{* * *} p<0.001,{ }^{* * * *} p<0.0001$ and NS, no significant. 
able to decrease tumor volume from tumors established 14 days prior (see Figure 6). Moreover, orexin-A slows PDX tumor growth and was able to decrease tumor volume from tumors established 40 days prior (see Figure 7). It is well known that the trafficking of various GPCRs differs depending on the time and concentration of exposure to ligands [27]. After a prolonged or repeated interaction with agonists, the total number of cell surface receptors can decrease by downregulation [28-30]. Nevertheless, OX1R expression in xenografted tumors was not altered by orexin treatment, suggesting that the receptor is not downregulated by the presence of its ligand.

Based on the success of the somatostatin receptor in targeting neuroendocrine tumors, novel tracers for peptide receptors such as analogs for prostate and breast cancers or for neo-angiogenesis labeling, are currently emerging [31]. Considering that $\mathrm{OX} 1 \mathrm{R}$ is widely expressed in PDAC, has high affinity for orexins, and is not expressed in nontumoral tissues, the development of isotopic orexin probes that could be used for the detection of precancerous PanIN lesions or micro-metastases by medical imaging should be tested in the future.

Actually, it is well known that a lot GPCR specific ligands were able to activate independently different signaling pathways [32]. These ligands also termed ligand-biased could stabilize different conformations of

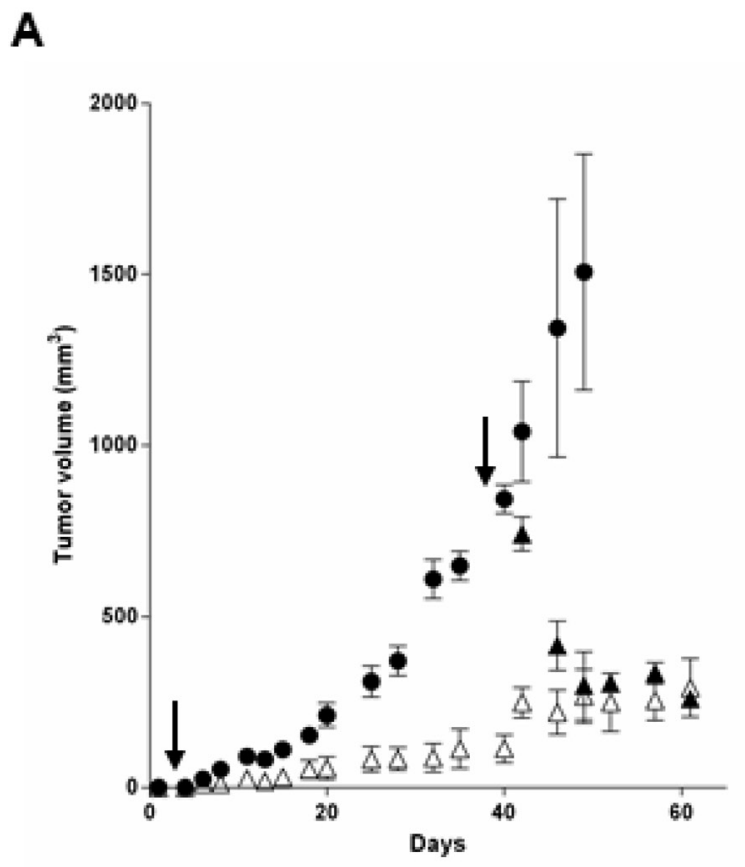

GPCR leading to promote various signaling pathways [32, 33]. An increasing number of studies described several non-peptidic chemical OX1R antagonists belonging to SORA (Single Orexin Receptors antagonist) and DORA species [22]. These molecules had been developed to inhibit the canonic intracellular calcium mobilization pathway related to the regulation by orexins of sleep control [22]. Suvorexant is the first agent to be approved in this new class of medication [22] and gained US Food and Drug Administration (FDA). In the present paper, we demonstrated that DORA such as suvorexant and more specifically, almorexant which are, as expected, full calcium pathway antagonists but are surprisingly, full proapoptotic pathway agonists suggesting that these molecules belong to ligand-biased family. Structurefunction relationship analysis by ala-scanning of orexin-B have demonstrated that some residues of the peptide were able to discriminate between calcium and proapoptotic pathways [34]. Similarly, almorexant which bind to OX1R with the same affinity than orexin-A could distinguish these two signaling pathways suggesting the existence of two independent molecular activation processes in $\mathrm{OX} 1 \mathrm{R}$ receptor. These observations indicate that $\mathrm{OX} 1 \mathrm{R}$ antagonists which are used in insomnia treatment could be used in PDAC therapy.

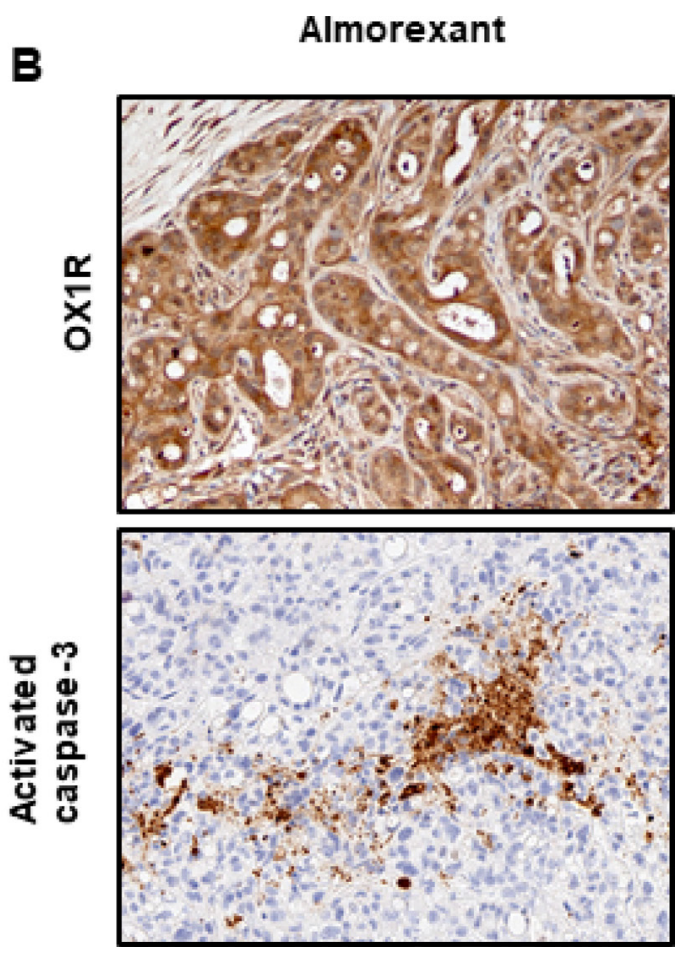

Figure 10: Effect of daily inoculation of almorexant on the growth of tumors developed by xenografting human PDCA cells in nude mice - (A) AsPC-1 cells were inoculated in the flank of nude mice at day 0 . Mice were injected daily intraperitoneally with $100 \mu 1$ of almorexant $(1.8 \mu \mathrm{mol} / \mathrm{kg})$ solutions starting at day $0(\Delta)$ or day $38(\mathbf{\Delta})$ or with $100 \mu 1$ of PBS $(\bullet)$ for controls. After 60 days of treatment, mice were sacrificed and tumor were then fixed. The development of tumors was followed by caliper measurement. Data are the means \pm SE of 6 tumors in each group. ${ }^{* * *} p<0.001$ versus control. (B) Indirect immunostaining of OX1R (top) and activated caspase-3 (bottom) in xenografted AsPC-1 tumors resected from nude mice. After necropsy, tumors from nude mice treated by almorexant were resected and paraformaldehyde-fixed and then were cut and used for immunohistochemistry. 
In conclusion, we have compellingly shown that OX1R is aberrantly expressed in PDAC, and that its activation by orexins and almorexant result in strong apoptosis and consequent cell growth inhibition in vivo, ex vivo and in vitro models. Based on our results, OX1R represents a new attractive and specific mediator of apoptosis against PDAC. The validation of orexin receptor as a target will lead to the development of new pharmacological molecules having a strong impact in the diagnosis and treatment of patients with PDAC. One of the possible paths of new therapeutical approaches could be the use of ligand-biased of OX1R such as almorexant.

\section{MATERIALS AND METHODS}

\section{Human surgical samples with PDAC, PanIN lesions and normal pancreas}

Seventy-three patients with PDAC treated with surgery (pancreato-duodenectomy $n=61$; left pancreatectomy $n=9$; total pancreatectomy $n=3$ ) from April 1997 to December 2004 were selected from the files of the Department of Pathology, Beaujon Hospital, Clichy, France. Charts from patients were retrospectively reviewed for clinical and pathological data. No patients received chemotherapy or radiation therapy preoperatively. The following data were recorded: age, gender, recurrence, disease-free survival (DFS) and overall survival (OS), tumor size, TNM stage, lymph node metastasis, differentiation. The studied population included 38 men and 35 women. The median age at surgery was 60 years (range 34-76). The tumor stage was T1 in 3 patients, T2 in 8 patients and T3 in 59 patients. The median tumor size was $30 \mathrm{~mm}$ (range $10-100 \mathrm{~mm}$ ). Lymph node metastases were present in 52 patients. Tumors were well- $(n=36)$, moderately- $(n=22)$ or poorly- $(n=12)$ differentiated. The median follow-up was 677 days (range 142-4294). Fifty-five patients $(78,6 \%)$ died of the disease during the time of the study. Tissue microarray (TMA) blocks were produced from representative paraffin blocks from the 73 PDAC using a tissue arrayer (Manual Tissue Arrayer-MTA1, Beecher Instruments, WI, USA). We also selected 10 normal pancreas, taken at a distance from tumors, without any pancreatitis or fibrosis lesions but with precancerous lesions (pancreatic intraepithelial lesions, PanIN) of low grade (PanIN-1 or PanIN-2; $n=16)$ and high grade (PanIN-3; $n=4)$ grade of dysplasia. For Ex Vivo human PDAC slices cultures, the effects of orexin-A were tested on human freshly surgically resected PDAC $(n=11)$. After pathological evaluation a tumor sample was sliced using a Leica Tissue Slicer (VT1200 S, Leica Biosystems Nussloch GmbH, Germany) into $300 \mu \mathrm{m}$-thick slices cultured in inserts already placed in 6-well plates with William's E medium, complemented with components including foetal calf serum, glucose, gentamicin and HEPES, under normoxic conditions. The use of human material was approved by the Institutional Review Board (CEERB GHU Paris Nord $\mathrm{N}^{\circ}$ IRB12-059 and 12-033).

\section{Cell lines cultures}

3 PDAC cell lines (AsPC-1, HPAF-II and SW 1990) from the American Type Culture Collection (ATCC, Manassas, VA) were grown according ATCC recommendations. The HPAF-II/OX1R, CHO/OX1R and $\mathrm{CHO} / \mathrm{OX} 2 \mathrm{R}$ cell lines, expressing recombinant human OX1R, were obtained as previously described [16]. The cell lines were incubated in the presence or absence of $1 \mu \mathrm{M}$ orexin-A (GL Biochemicals, Shangaï, China) or suvorexant or almorexant (MedChemExpress, Sollentuna, Sweeden).

\section{Tumorigenicity assay in nude mice xenografts}

AsPC-1, HPAF-II and HPAF-II/OX1R cells were inoculated subcutaneously into the flank of anesthetized mice as previously described [8]. In an effort to develop more reliable preclinical models, we have established a subcutaneous patient-derived xenograft (PDX) model. Tumoral cells isolated from a human pancreatic cancer were inoculated into the flank of mice. Tumor development was followed by caliper measurements in 2 dimensions ( $\mathrm{L}$ and $\mathrm{W}$ ), and the volume (V) of the tumor was calculated $[35,36]$. Orexin-A or almorexant was administered by intraperitoneal injections, starting the day of cell lines subcutaneous inoculation or 14 days (AsPC-1 cells) or 40 days (PDX cells) after this date when tumours were established. Control mice received PBS. After necropsy, tumors were then resected, weighted and analyzed.

\section{Immunohistochemical procedures}

Immunohistochemistry was performed on formalinfixed paraffin-embedded normal pancreas, PanIN lesions, tumor tissue (from human tissue-microarrays, human tissue slices and mice xenografts) and on cell lines in pellets fixed in formalin and embedded in cell blocks (Shandon Cytoblock; Thermo Scientific; USA), with an automated immunohistochemical stainer according to the manufacturer's guidelines (automate BOND, Leica Microsystems). Slides were immunolabeled with antibodies against OX1R (Life Technology, PA5-33837, polyclonal rabbit, 1/100), activated caspase-3 (Abgent, E87-77, polyclonal rabbit, 1/100) or Ki-67 (DAKO, clone MIB-1, monoclonal mouse, 1/100). OX1R evaluation was performed in human normal pancreas, PanIN lesions, PDAC TMA, PDAC slices, in xenografted tumors and in cell lines by calculating a score (0-300) obtained by multiplying the intensity (negative, 0; weak, 1; moderate, 2; and strong, 3) by the percentage of stained cells. Internal positive controls consisted of normal pancreatic islets while the $\mathrm{HEK} / \mathrm{hOX} 1 \mathrm{R}$ cell line served 
as an external positive control. The evaluation of apoptosis was performed in PDAC slices, tumor cell lines and xenografted tumours by evaluation of the percentage of caspase-3 positive tumour cells. External positive controls consisted of normal lymph nodes. The evaluation of $\mathrm{Ki}-$ 67 was performed in PDAC slices by evaluation of the percentage of Ki-67 positive tumor cells. External positive controls consisted of normal lymph nodes.

\section{Immunoprecipitation of SHP2}

AsPC-1 or HPAF-II cells were pretreated $24 \mathrm{~h}$ without or with $50 \mu \mathrm{M}$ SHP1/2 inhibitor NSC-87877. Semiconfluent cells were then treated with $1 \mu \mathrm{M}$ orexin-A or $1 \mu \mathrm{M}$ almorexant in fresh culture medium at $37^{\circ} \mathrm{C}$ for $5 \mathrm{~min}$. Cells were collected and lysed in $50 \mathrm{mM}$ Tris- $\mathrm{HCl}$ buffer $\mathrm{pH} 7.4$ containing $0.25 \% \mathrm{Na}$ deoxycholate, 150 $\mathrm{mM} \mathrm{NaCl}, 1 \%$ Nonidet P-40 and $1 \mathrm{mM}$ EGTA. Proteins $(500 \mu \mathrm{g})$ were then incubated with $2 \mu \mathrm{g}$ of anti-SHP2 antibodies overnight at $4^{\circ} \mathrm{C}$. Protein immunoprecipitation was performed according to the manufacturer's instructions using the Seize protein $\mathrm{G}$ immunoprecipitation kit (Pierce, Rockford, IL, USA). Then, immunoprecipitated proteins suspended in Laemmli buffer were loaded onto a $10 \%$ SDS-polyacrylamide gel, transferred to a nitrocellulose membrane, and immunoblotted with antiPhosphoTyrosine (1:1000 dilution) or anti-SHP2 (1:1000 dilution) antibodies. Immunocomplexes were revealed with secondary peroxidase conjugated antibodies, using a chemiluminescent kit.

\section{RT-PCR assays}

RNA was extracted from cultured cells lines including AsPC-1, SW 1990, HPAF-II, HPAF-II/OX1R, $\mathrm{CHO} / \mathrm{OX} 1 \mathrm{R}$ and $\mathrm{CHO} / \mathrm{OX} 2 \mathrm{R}$ by using $\mathrm{RNeasy}^{\circledR}$ Mini Kit (Qiagen). PCR amplifications using OX1R sense primer (5'-CCTGTGCCTCCAGACTATGA-3') and OX1R antisense primer (5'-ACACTGCTGACATTCCATGA-3'), OX2R sense primer (5'-TAGTTCCTCAGCTGCCTATC-3') and OX2R antisense primer (5'-CGTCCTCATGTGGTGGTTCT-3') or $\beta$-actin sense primer (5'-ATCTGGCACCACACCTTCTACA ATGAGCTGCG-3') and $\beta$-actin antisense primer (5'-CGTCA TACTCCTGCTTGCTGATCCACATCTGC-3') were carried out as previously described [15].

\section{Quantification of apoptotic cells by annexin V labelling}

AsPC-1, SW 1990, HPAF-II and HPAF-II/hOX1R cells (seeded at $5 \times 10^{4}$ cells/well) were grown as described above. The culture medium was then replaced every $24 \mathrm{hr}$ with fresh medium with or without $1 \mu \mathrm{M}$ orexin-A or almorexant in the presence or in the absence of the SHP-2 inhibitor, NSC-87877 $(50 \mu \mathrm{M})$ (Calbiochem, VWR International SAS, France). After $48 \mathrm{hr}$, apoptotic cells were determined using the Guava Nexin ${ }^{\mathrm{TM}}$ kit (Guava
Technologies, Hayward, CA, USA [15]. Results are expressed as the percentage of apoptotic phycoerythrinlabelled Annexin V (Annexin V-PE) positive cells and are the means of 3 independent analyses.

\section{Caspase- 3 activity detection}

AsPC-1 cells were pretreated $24 \mathrm{~h}$ without or with $50 \mu \mathrm{M} \mathrm{SHP} 1 / 2$ inhibitor NSC-87877. 5.10 semiconfluent cells were then treated with $1 \mu \mathrm{M}$ orexin-A or $1 \mu \mathrm{M}$ almorexant in fresh culture medium at $37^{\circ} \mathrm{C}$ for $24 \mathrm{~h}$. Caspase-3 activity detection was performed according to the manufacturer's instructions using the caspase-3 assay colorimetric kit (\#ab39401, Abcam, Paris, France). The caspase- 3 activity measurement is based on spectrophotometric detection at $405 \mathrm{~nm}$ of the chromophore $\mathrm{p}$-nitroaniline after cleavage by the activated caspase-3 from the labeled substrate DEVD-p-nitroaniline. Results are expressed as the optic density (O.D.) at $405 \mathrm{~nm}$ for $200 \mu \mathrm{g}$ of protein for each sample and are the means of 3 independent analyses.

\section{Statistical analysis}

Mann-Whitney non-parametric tests were performed to compare categorical with continuous variables where the number of categories was two. When the number of categories was greater than two, ANOVA (analysis of variance) tests were used instead. Data were analyzed with the GraphPad Prism 5.04 statistical software for Windows. All statistical tests were 2-sided. The critical level of statistical significance was set at $p<0.05$.

\section{Author contributions}

SD, DS, PB, VG, JC and TV performed all the experiments and analysed the results. VR performed the statistical analyses. AC, AC and TV designed the experiments and wrote the manuscript. AS, PB, VP and PR revised the manuscript critically for important intellectual content. All authors approved the final version for publication.

\section{ACKNOWLEDGMENTS}

The authors wish to thank Dr. Martine Torres for critical reading of the manuscript and editorial help.

\section{CONFLICTS OF INTEREST}

No potential conflicts of interest were disclosed.

\section{FUNDING}

This study was supported by INSERM U1149/ The Inflammation Research Center (CRI), The "Institut 
Nationnal du Cancer (INCA)" (Translational project $\mathrm{N}^{\circ}$ 2013-213) and the "Ligue Contre le Cancer" (RS 12/75-64). SD was granted by the "Ligue Contre le Cancer" (GB/MA/CD/EP-12062).

\section{REFERENCES}

1. Rahib L, Smith BD, Aizenberg R, Rosenzweig AB, Fleshman JM, Matrisian LM. Projecting cancer incidence and deaths to 2030: the unexpected burden of thyroid, liver, and pancreas cancers in the United States. Cancer Res. 2014; 74:2913-21.

2. Ryan DP, Hong TS, Bardeesy N. Pancreatic adenocarcinoma. N Engl J Med. 2014; 371:2140-41.

3. Neuzillet C, Tijeras-Raballand A, Bourget P, Cros J, Couvelard A, Sauvanet A, Vullierme MP, Tournigand C, Hammel P. State of the art and future directions of pancreatic ductal adenocarcinoma therapy. Pharmacol Ther. 2015; 155:80-104.

4. Siegel RL, Miller KD, Jemal A. Cancer statistics, 2016. CA Cancer J Clin. 2016; 66:7-30.

5. Garcea G, Neal CP, Pattenden CJ, Steward WP, Berry DP. Molecular prognostic markers in pancreatic cancer: A systematic review. Eur J Cancer. 2005; 41:2213-36.

6. Lappano R, Maggiolini M. G protein-coupled receptors: novel targets for drug discovery in cancer. Nat Rev Drug Discov. 2011; 10:47-60.

7. O’Hayre M, Degese MS, Gutkind JS. Novel insights into G protein and $\mathrm{G}$ protein-coupled receptor signaling in cancer. Curr Opin Cell Biol. 2014; 27:126-35.

8. Voisin T, Firar AE, Fasseu M, Rouyer-Fessard C, Descatoire V, Walker F, Paradis V, Bedossa P, Henin D, Lehy T, Laburthe M. Aberrant Expression of OX1 Receptors for Orexins in Colon Cancers and Liver Metastases: an Openable Gate to Apoptosis. Cancer Res. 2011; 71:3341-51.

9. Sakurai T, Amemiya A, Ishii M, Matsuzaki I, Chemelli RM, Tanaka H, Williams SC, Richardson JA, Kozlowski GP, Wilson S, Arch JR, Buckingham RE, Haynes AC, et al. Orexins and Orexin Receptors: A Family of Hypothalamic Neuropeptides and G Protein-Coupled Receptors that Regulate Feeding Behavior. Cell. 1998; 92:573-85.

10. Ohno K, Hondo M, Sakurai T. Cholinergic Regulation of Orexin/Hypocretin Neurons Through M3 Muscarinic Receptor in Mice. J Pharmacol Sci. 2008; 106:485-91.

11. Voisin T, Rouet-Benzineb P, Reuter N, Laburthe M. Orexins and their receptors: structural aspects and role in peripheral tissues. Cell Mol Life Sci. 2003; 60:72-87.

12. Heinonen MV, Purhonen AK, Mäkelä KA, Herzig KH. Functions of orexins in peripheral tissues. Acta Physiol. 2008; 192:471-85.

13. Jöhren O, Neidert SJ, Kummer M, Dendorfer A, Dominiak P. Prepro-Orexin and Orexin receptor mRNAs are differentially expressed in peripheral tissues of male and female rats. Endocrinology. 2001; 142:3324-31.
14. Laburthe M, Voisin T, El Firar A. Orexins/hypocretins and orexin receptors in apoptosis: a mini-review. Acta Physiol. 2010; 198:393-402.

15. Rouet-Benzineb P, Rouyer-Fessard C, Jarry A, Avondo V, Pouzet C, Yanagisawa M, Laboisse C, Laburthe M, Voisin T. Orexins Acting at Native OX1 Receptor in Colon Cancer and Neuroblastoma Cells or at Recombinant OX1 Receptor Suppress Cell Growth by Inducing Apoptosis. J Biol Chem. 2004; 279:45875-86.

16. Voisin T, El Firar A, Rouyer-Fessard C, Gratio V, Laburthe M. A hallmark of immunoreceptor, the tyrosine-based inhibitory motif ITIM, is present in the G protein-coupled receptor OX1R for orexins and drives apoptosis: a novel mechanism. FASEB J. 2008; 22:1993-2002.

17. El Firar A, Voisin T, Rouyer-Fessard C, Ostuni MA, Couvineau A, Laburthe M. Discovery of a functional immunoreceptor tyrosine-based switch motif in a 7-transmembrane-spanning receptor: role in the orexin receptor OX1R-driven apoptosis. FASEB J. 2009; 23:4069-80.

18. Laburthe M, Voisin T. The orexin receptor OX1R in colon cancer: a promising therapeutic target and a new paradigm in $\mathrm{G}$ protein-coupled receptor signalling through ITIMs. Br J Pharmacol. 2012; 165:1678-87.

19. Hamacher R, Schmid RM, Saur D, Schneider G. Apoptotic pathways in pancreatic ductal adenocarcinoma. Mol Cancer. 2008; 7:64.

20. Iovanna J, Mallmann MC, Gonçalves A, Turrini O, Dagorn JC. Current knowledge on pancreatic cancer. Front Oncol. 2012; $2: 6$.

21. Müerköster SS, Werbing V, Koch D, Sipos B, Ammerpohl O, Kalthoff H, Tsao MS, Fölsch UR, Schäfer H. Role of myofibroblasts in innate chemoresistance of pancreatic carcinoma-Epigenetic downregulation of caspases. Int $\mathrm{J}$ Cancer. 2008; 123:1751-60.

22. Norman JL, Anderson SL. Novel class of medications, orexin receptor antagonists, in the treatment of insomnia - critical appraisal of suvorexant. Nat Sci Sleep. 2016; 8:239-47

23. Capella C, Albarello L, Capelli P, Sessa F, Zamboni G. Carcinoma of the exocrine pancreas: The histology report. Dig Liver Dis. 2011; 43:S282-92.

24. Scartozzi M, Bearzi I, Berardi R, Mandolesi A, Fabris G, Cascinu S. Epidermal Growth Factor Receptor (EGFR) Status in Primary Colorectal Tumors Does Not Correlate With EGFR Expression in Related Metastatic Sites: Implications for Treatment With EGFR-Targeted Monoclonal Antibodies. J Clin Oncol. 2004; 22:4772-78.

25. Bralet MP, Paule B, Adam R, Guettier C. Loss of Epidermal Growth Factor Receptor Expression in Lymph Node and Liver Metastases of Colon Carcinoma. J Clin Oncol. 2005; 23:5844-5.

26. Liu KC, Yen CY, Wu RS, Yang JS, Lu HF, Lu KW, Lo C, Chen HY, Tang NY, Wu CC, Chung JG. The roles of endoplasmic reticulum stress and mitochondrial apoptotic signaling pathway in quercetin-mediated cell death of 
human prostate cancer PC-3 cells. Environ Toxicol. 2014; 29:428-39.

27. Hanyaloglu AC, von Zastrow M. Regulation of GPCRs by endocytic membrane trafficking and its potential implications. Annu Rev Pharmacol Toxicol. 2008; 48:537-68.

28. Tsao P, von Zastrow M. Downregulation of G proteincoupled receptors. Curr Opin Neurobio. 2000; 10:365-69.

29. Tsao P, Cao T, von Zastrow M. Role of endocytosis in mediating downregulation of G-protein-coupled receptors. Trends Pharmacol Sci. 2001; 22:91-6.

30. Boivin GA, Beninger RJ. Differential effects of dopamine and AMPA receptor antagonists on the expression of conditioned avoidance responding in rats. Behav Neurosci. 2008; 122:377-84.

31. Reubi JC, Maecke HR. Peptide-Based Probes for Cancer Imaging. J Nucl Med. 2008; 49:1735-8.

32. Costa-Neto CM, Parreiras-E-Silva LT, Bouvier M. A Pluridimensional View of Biased Agonism. Mol Pharmacol. 2016; 90:587-95.
33. Shonberg J, Lopez L, Scammells PJ, Christopoulos A, Capuano B, Lane JR. Biased agonism at G protein-coupled receptors: the promise and the challenges-a medicinal chemistry perspective. Med Res Rev. 2014; 34:1286-330.

34. Nicole P, Couvineau P, Jamin N, Voisin T, Couvineau A. Crucial role of the orexin-B C-terminus in the induction of OX1 receptor-mediated apoptosis: analysis by alanine scanning, molecular modelling and site-directed mutagenesis. Br J Pharmacol. 2015; 172:5211-23.

35. Maoret JJ, Anini Y, Rouyer-Fessard C, Gully D, Laburthe M. Neurotensin and a non-peptide neurotensin receptor antagonist control human colon cancer cell growth in cell culture and in cells xenografted into nude mice. Int $\mathrm{J}$ Cancer. 1999; 80:448-54.

36. Stragand JJ, Barlogie B, White RA, Drewinko B. Biological Properties of the Human Colonic Adenocarcinoma Cell Line SW 620 Grown as a Xenograft in the Athymic Mouse. Cancer Res. 1981; 41:3364-69. 